\title{
Enhanced oxidative mechanisms in immunologically activated versus elicited polymorphonuclear neutrophils: correlations with fungicidal activity
}

\author{
CHRISTINE J. MORRISON*, R. A. ISENBERG and D. A. STEVENS
}

Division of Infectious Diseases, Department of Medicine, Santa Clara Valley Medical Center and Institute for Medical Research, 751 South Bascom Avenue, San Jose, CA 95128 and Stanford University Medical School, Stanford, CA 94305, USA

\begin{abstract}
Summary. Peritoneal polymorphonuclear neutrophils (PMN) from mice were tested for their ability to kill the yeast form of Blastomyces dermatitidis (Bd) in vitro and for their fungicidal mechanisms. PMN elicited from immune mice by the intraperitoneal injection of non-viable Bd (referred to as immunologically activated PMN or ActPMN) showed significantly enhanced fungicidal activity in comparison with PMN elicited with thioglycollate medium (ThioPMN) [means $=44.7 \%$ (SD 12.8\%) and $16.4 \%(\mathrm{SD} 9 \cdot 2 \%)$ killed; $\mathrm{n}=14 ; \mathrm{p}<0.001]$. Production of superoxide anion $\left(0_{2}{ }^{-}\right)$ by ActPMN after stimulation with phorbol myristate acetate was enhanced in comparison with production by ThioPMN. Superoxide dismutase, which removes $\mathrm{O}_{2}{ }^{-}$, inhibited ActPMN killing by $75 \%(\mathrm{p}<0.001)$ when added to cultures immediately before challenge with Bd (optimal concentration: $6000 \mathrm{U} / \mathrm{ml}$ ). Sodium azide, which inhibits myeloperoxidase and scavenges singlet oxygen $\left({ }^{1} \mathrm{O}_{2}\right)$, and catalase, which breaks down hydrogen peroxide $\left(\mathrm{H}_{2} \mathrm{O}_{2}\right)$, inhibited ActPMN killing by $64 \%(\mathrm{p}<0.001)$ and $52 \%(\mathrm{p}<0.001)$, with optimal concentrations of $1 \mathrm{~mm}$ and $10000 \mathrm{U} / \mathrm{ml}$, respectively. Two agents that both scavenge ${ }^{1} \mathrm{O}_{2}$ and antagonise hypochlorous acid $\left(\mathrm{HOCl}^{-}\right)$, histidine and tryptophan, were also powerful inhibitors of ActPMN killing. Quenchers of hydroxyl radical $(\cdot \mathrm{OH})$, dimethylsulfoxide and sodium benzoate, had less effect, and required higher concentrations. These data suggest that the enhanced killing of Bd by ActPMN involves one or more oxidative mechanisms, and that there is a prominent role for $\mathrm{O}_{2}{ }^{-}$, either directly or as a precursor of other active oxygen species, a probable role for $\mathrm{H}_{2} \mathrm{O}_{2}$, and possible roles for ${ }^{1} \mathrm{O}_{2}, \mathrm{HOCl}^{-}$, and $\cdot \mathrm{OH}$.
\end{abstract}

\section{Introduction}

Upon interaction with micro-organisms, polymorphonuclear neutrophils (PMN) display enhanced oxidative metabolism including increased consumption of oxygen, increased hexose monophosphate shunt activity, and the production of chemically reactive metabolites of oxygen such as superoxide anion $\left(\mathrm{O}_{2}{ }^{-}\right)$and hydrogen peroxide $\left(\mathrm{H}_{2} \mathrm{O}_{2}\right)$ (Klebanoff and Clark, 1978). $\mathrm{H}_{2} \mathrm{O}_{2}$ and $\mathrm{O}_{2}{ }^{-}$can react to produce additional metabolites (Badwey and Karnovsky, 1980) including hydroxyl radical $(\cdot \mathrm{OH})$ and singlet oxygen $\left({ }^{1} \mathrm{O}_{2}\right) . \mathrm{H}_{2} \mathrm{O}_{2}$ in the presence of halide and myeloperoxidase (MPO), an enzyme present in $\mathrm{PMN}$, can also generate halogenated oxidative anions such as hypochlorous

Received 5 Jan. 1987; revised version accepted 8 May 1987. acid $\left(\mathrm{HOCl}^{-}\right)$(Klebanoff and Clark, 1978). The reactive oxygen species generated by $\mathrm{PMN}$ mediate much of their microbicidal activity (Johnston et al., 1975; Klebanoff and Clark, 1978) although oxygen independent killing mechanisms may also be involved (Lehrer et al., 1975; Klebanoff and Clark, 1978; Spitznagel and Shafer, 1985).

It was previously reported that immunologically activated PMN (ActPMN), induced in Blastomyces dermatitidis-immune mice by intraperitoneal injection of $\boldsymbol{B}$. dermatitidis antigen, had enhanced fungicidal activity in vitro in comparison with PMN elicited by thioglycollate medium (ThioPMN), and it was suggested they had an increased oxidative burst in chemiluminescence studies (Brummer et al., 1984, 1985). In a more specific investigation of the oxygen metabolites involved in the killing of $B$. dermatitidis by PMN, the production of $\mathrm{O}_{2}{ }^{-}$by 
ActPMN or ThioPMN after stimulation with phorbol myristate acetate (PMA) has been measured and the effect of scavengers of active oxygen species on the PMN killing of $B$. dermatitidis yeasts in vitro has been examined; the results are reported below.

\section{Materials and methods}

\section{Animals \\ Pathogen-free BALB/cByJIMR male mice (Institute for Medical Research, San Jose, CA) 8-12 weeks old were used.}

\section{Fungi}

Inocula of $B$. dermatitidis, strain ATCC 26199, were prepared for in-vitro challenge from cultures grown for 48-72h on blood agar (BA) incubated at $35^{\circ} \mathrm{C}$. Fungal cells were washed and appropriate dilutions cultured in triplicate on BA to determine the number of $\mathrm{cfu} / \mathrm{ml}$. $B$. dermatitidis cells frozen and thawed 12 times in an acetone-dry ice bath or stored at $-70^{\circ} \mathrm{C}$ for more than 2 years were used as non-viable fungal antigen.

\section{Reagents and media}

These were: tissue culture medium (TCM)-RPMI1640 medium supplemented with heat-inactivated fetal bovine serum $10 \% \mathrm{v} / \mathrm{v}$ and $(/ \mathrm{ml})$ penicillin $100 \mathrm{U}$ plus streptomycin $100 \mu \mathrm{g}$ (Gibco Laboratories, Grand Island, NY); Hanks's Balanced Salt Solution without phenol red (HBSS) (Gibco); preservative-free ammonium heparin (American Scientific Products, Sunnyvale, CA); metrizamide (2-(3-acetamido - 5 - N - methylacetamido - 2, 4, 6triiodobenzamido)-2-deoxy-D-glucose) (Sigma Chemical Company, St Louis, MO), a $35.5 \%$ isotonic solution in distilled water. Metrizamide gradients were made by diluting the $35.5 \%$ solution in Dulbecco's phosphatebuffered saline (Gibco). Ferricytochrome c (type VI, from horse heart), phorbol 12-myristate 13-acetate (PMA), superoxide dismutase (from bovine erythrocytes) (SOD), sodium azide (AZ), and dimethylsulphoxide (DMSO) were from Sigma. Catalase (from bovine liver) (Sigma) was dialysed against $0.05 \mathrm{M}$ potassium phosphate buffer,

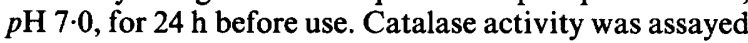
by the method of Beers and Sizer (1952) in which the disappearance of $\mathrm{H}_{2} \mathrm{O}_{2}$ was followed spectrophotometrically at $240 \mathrm{~nm}$. Heat-inactivated catalase and SOD were prepared by autoclaving the enzymes for $15 \mathrm{~min}$ at $121^{\circ} \mathrm{C}$. Triton X-100 (New England Nuclear, Boston, MA), tryptophan (Matheson, Coleman and Bell, Norwood, $\mathrm{OH}$ ), histidine (Eastman Kodak, Rochester, NY), and sodium benzoate (Mallinkrodt, St Louis, MO) were used as stated.

\section{Immunisation of mice}

Mice given $20000 \mathrm{cfu}$ of $B$. dermatitidis subcutaneously at two dorsal sites are referred to as immune mice after resolution of the infection over a 4-week period (Morozumi et al., 1982).

\section{Polymorphonuclear neutrophils (PMN)}

Peritoneal exudate cells (PEC) enriched for PMN were elicited by injecting $1 \mathrm{ml}$ of thioglycollate broth (Clinical Standards Laboratories, Carson, CA) intraperitoneally into mice $24 \mathrm{~h}$ before cell harvest. Immunologically activated PMN were obtained by injecting $500 \mu \mathrm{g}$ (wet weight) of non-viable $B$. dermatitidis cells in $0.5 \mathrm{ml}$ of isotonic saline intraperitoneally into immune mice $24 \mathrm{~h}$ before collection. PEC obtained after either stimulus were collected by repeated lavage of the peritoneal cavity with heparinised Eagle's Minimal Essential Medium (MEM) (Gibco), suspending the cells in $0.2 \%$ saline to lyse erythrocytes, reconstituting to isotonicity with $1.6 \%$ saline, washing once in isotonic saline and counting in a haemocytometer. These PEC were purified (Brummer and Stevens, 1983) by layering $1 \mathrm{ml}$ of (3-4) $\times 10^{7}$ cells on a metrizamide gradient $(1.5 \mathrm{ml}$ of $14.5 \%$ over $1.5 \mathrm{ml}$ of $15.5 \%$ metrizamide) and centrifuging at $500 \mathrm{~g}$ for $20 \mathrm{~min}$. Pelleted cells were washed once, resuspended in TCM and counted in a haemocytometer. The purified ThioPMN preparation was $83.6 \%$ (SD 5.6\%) PMN, and the purified preparation of ActPMN was $79.9 \%$ (SD $6.6 \%)$ PMN $(n=8)$.

\section{Determination of $\mathrm{O}_{2}{ }^{-}$production}

PMN were suspended in HBSS, dispensed into 24-well flat-bottom microtest plates-1.0 ml/well; (3-6) $\times 10^{6}$ cells $/ \mathrm{ml}$ (Corning Glass Works, Corning, NY)-and incubated for $1-2 \mathrm{~h}$ at $37^{\circ} \mathrm{C}$ in $\mathrm{CO}_{2} 5 \%$, air $95 \%$. Nonadherent cells were removed and adherent cells were washed once with isotonic saline before the assay mixture was added to each well. The adherent cells, for ThioPMN and ActPMN, were both $92 \%$ PMN. The assay mixture ( $2 \mathrm{ml}$ total volume/well) consisted of HBSS plus ferricytochrome c $40-80 \mu \mathrm{g} / \mathrm{ml}$, PMA 2-4 $\mu \mathrm{g} / \mathrm{ml}$ and fresh normal mouse serum $5-10 \%$. SOD in $0.2 \mathrm{ml}$ of HBSS $(6000 \mathrm{U} / \mathrm{ml}$, final concentration) was substituted for $0 \cdot 2$ $\mathrm{ml}$ of HBSS in selected wells to determine the SODinhibitable reduction of ferricytochrome c. After incubation for $1 \mathrm{~h}$ at $37^{\circ} \mathrm{C}$ in $\mathrm{CO}_{2} 5 \%$, air $95 \%$, the fluid was removed from the wells and placed in test tubes on ice. The test tubes were then centrifuged at $1000 \mathrm{~g}$ for $10 \mathrm{~min}$ at $4{ }^{\circ} \mathrm{C}$ and the absorbance at $550 \mathrm{~nm}$ of the supernates measured in a Beckman Acta III (Beckman Inc., Fullerton, CA) double beam spectrophotometer. The number of nmol of ferricytochrome $c$ reduced was determined with an extinction coefficient of $2.1 \times 10^{4}$ $\mathbf{M}^{-1} \mathrm{~cm}^{-1}$. Fluid from wells containing PMN and all assay mixture components except PMA was assessed for background reduction of ferricytochrome $c$ and the values obtained were subtracted from those of test samples. 
Adherent cells were washed twice with HBSS and disrupted by exposure to $0.5 \mathrm{ml}$ of $0.2 \%$ Triton X-100 detergent. Each well was then scraped with a pasteur pipette. The protein content of cell digests was determined by the method of Lowry et al. (1951) with bovine serum albumin as standard.

\section{Co-cultures of PMN and B. dermatitidis}

PMN were suspended in TCM and dispensed $(0.1 \mathrm{ml}$ of $5 \times 10^{6} / \mathrm{ml}$ ) into 96-well flat-bottom microtest plates (Corning Glass Works), and incubated for $1 \mathrm{~h}$ at $37^{\circ} \mathrm{C}$ in $\mathrm{CO}_{2} 5 \%$, air $95 \%$. B. dermatitidis $\left(0 \cdot 1 \mathrm{ml}\right.$ of $1 \times 10^{4} \mathrm{cfu} /$ ml) was added plus fresh normal mouse serum $0.02 \mathrm{ml} /$ well. To selected wells, various potential inhibitors were added immediately before the addition of $B$. dermatitidis.

Co-cultures were incubated for 2 or $3 \mathrm{~h}$ at $37^{\circ} \mathrm{C}$ in $\mathrm{CO}_{2}$ $5 \%$, air $95 \%$ and harvested with distilled water (Brummer and Stevens, 1984). Dilutions were made in isotonic saline and the number of cfu/well was determined by culture on BA. The percentage reduction of inoculum cfu was determined with the formula:

$$
[1-(\text { co-culture cfu/inoculum cfu })] \times 100
$$

\section{Statistical analyses}

Student's $t$ test was used to determine the statistical significance between groups.

\section{Results}

\section{Killing of $B$. dermatitidis by activated versus elicited PMN}

It was previously reported that immunologically activated PMN (ActPMN) had an enhanced capacity to kill $B$. dermatitidis yeast cells in vitro in comparison with thioglycollate elicited PMN (ThioPMN) (Brummer et al., 1985). In those studies, thioglycollate was injected intraperitoneally $4 \mathrm{~h}$ before peritoneal exudate cell collection. To follow more closely the elicitation schedule used for ActPMN (Brummer et al., 1985), where whole, killed $B$. dermatitidis were injected intraperitoneally $24 \mathrm{~h}$ before PEC collection, thioglycollate was injected $24 \mathrm{~h}$ before PEC harvest for elicitation of ThioPMN in these experiments. This 24-h ThioPMN population isolated after centrifugation on a single metrizamide gradient was studied extensively for the first time. Whereas PMN elicited by thioglycollate injection $4 \mathrm{~h}$ before failed to kill $B$. dermatitidis yeasts (0-8\% reduction of inoculum cfu) (Brummer et al., 1984, 1985), these 24-h ThioPMN killed a small (16.4 SD 9.2\%, mean and SD) but significant $(p<0.001)$ part of the fungal inoculum (figure). During the co-culture period, the cfu in the absence of PMN did not significantly decline $(1.4 \mathrm{SD} 9.0 \%)$, and thus killing by these PMN was also significant $(\mathrm{p}<0 \cdot 001)$ if the post-coculture period cfu are used for comparison. ActPMN demonstrated a significantly enhanced ability to kill $B$. dermatitidis in vitro (44.7 SD $12.8 \%)$ compared with 24-h ThioPMN ( $<<0.001)$ (figure), as well as compared with 4-h ThioPMN as previously reported (Brummer et al., 1984, 1985).

\section{Production of $\mathrm{O}_{2}{ }^{-}$by activated versus elicited $P M N$}

It was previously reported that ActPMN produced a 10-fold greater chemiluminescent burst 15 min after stimulation with $B$. dermatitidis cells than did ThioPMN (Brummer et al., 1985). Luminol enhanced chemiluminescence by phagocytic cells has been attributed to the production of active oxygen species that depend upon $\mathrm{O}_{2}{ }^{-}$for their formation; therefore, the production of $\mathrm{O}_{2}^{-}$by ActPMN or ThioPMN was examined to determine whether $\mathrm{O}_{2}^{-}$production correlated with fungicidal activity.

After stimulation with PMA, ActPMN produced more than twice the quantity of $\mathrm{O}_{2}^{-}$produced by ThioPMN $(\mathrm{p}<0.01)$ (table I). No differences in the numbers of cells adhering to culture plates or in the quantity of adherent cell protein were observed between ThioPMN and ActPMN cultures; 24 and $25 \%$ of ThioPMN and ActPMN preparations, respectively, were nonadherent. The two preparations resulted in $0.022 \mathrm{SD} 0.0007$ and $0.021 \mathrm{SD}$ $0.0007 \mathrm{mg}$ adherent cell protein $/ 10^{6}$ cells, respectively.

Table I. Production of $\mathrm{O}_{2}^{-}$by ActPMN and ThioPMN after stimulation with phorbol myristate acetate

\begin{tabular}{l|cc}
\hline & \multicolumn{2}{|c}{$0_{2}{ }^{-}$released* } \\
\cline { 2 - 3 } PMN type & nmoles $\mathrm{O}_{2}{ }^{-} / 10^{6} \mathrm{PMN} / \mathrm{h}$ & $\begin{array}{r}\text { nmoles } \mathrm{O}_{2}{ }^{-} / \mathrm{mg} \\
\text { cell protein/h }\end{array}$ \\
\hline ThioPMN & $1 \cdot 20 \mathrm{SD} 0 \cdot 48(6)$ & $54 \cdot 6 \mathrm{SD} 21 \cdot 8(6)$ \\
ActPMN & $3 \cdot 10 \mathrm{SD} 1 \cdot 28(6)$ & $149 \cdot 5 \mathrm{SD} 63 \cdot 5(6)$ \\
\hline
\end{tabular}

* $\mathrm{O}_{2}{ }^{-}$production was measured in a ferricytochrome c reduction assay. Mean number of SOD $(6000 \mathrm{U} / \mathrm{ml})$-inhibitable nmoles of $\mathrm{O}_{2}{ }^{-}$produced $/ 10^{6} \mathrm{PMN}$ or $\mathrm{mg}$ cell protein and the SD from the mean for the number of experiments given in parentheses. Values shown for ThioPMN were significantly different from those for ActPMN $(p<0 \cdot 01)$. 
Effect of SOD on killing of $B$. dermatitidis by activated versus elicited PMN

Exogenous SOD, a scavenger of $\mathrm{O}_{2}{ }^{-}$, inhibited ActPMN killing by as much as $74.9 \%$ when added to cultures immediately before challenge with $B$. dermatitidis (figure). The optimum SOD concentration tested was $6000 \mathrm{U} / \mathrm{ml}$, with significant inhibition of killing at $3000-\geq 9000 \mathrm{U} / \mathrm{ml}$ (maximum concentration tested, $66000 \mathrm{U} / \mathrm{ml}$ ) (figure). The $p$ values for the comparisons between SOD treated and untreated ActPMN were $\mathrm{p}<0.005, \mathrm{p}<0.001$ and $\mathrm{p}<0.01$ for 3000,6000 , and $\geqslant 9000 \mathrm{U} / \mathrm{ml}$, respectively. Enzyme concentrations $\leqslant 1000 \mathrm{U} / \mathrm{ml}$ or heated SOD did not significantly inhibit the ActPMN fungicidal capacity (figure). The addition of catalase $(20000 \mathrm{U} / \mathrm{ml})$ in conjunction with SOD $(6000 \mathrm{U} / \mathrm{ml})$ did not inhibit fungal killing any more than SOD alone (figure). SOD had no direct effect on $B$. dermatitidis viability and did not inhibit fungal killing by Thio PMN at the concentrations tested $(\leqslant 1000,3000,6000$, or $\geqslant 9000 \mathrm{U} / \mathrm{ml}$ in $4-6$ experiments at each of these concentrations).

\section{Effect of catalase on killing of $B$. dermatitidis by activated versus elicited PMN}

Catalase, an enzyme that catalyses the breakdown of $\mathrm{H}_{2} \mathrm{O}_{2}$ to $\mathrm{H}_{2} \mathrm{O}$ and $\mathrm{O}_{2}$ (Beers and Sizer,
1952), inhibited the ActPMN-mediated killing of $B$. dermatitidis by $51.9 \%(\mathrm{p}<0.001)$ when added to cultures at an optimum concentration of $10000 \mathrm{U} /$ ml(table II). Catalase concentrations above or below the optimum were not significantly protective, although inhibition of killing was suggested (table II). Heated catalase $(20000 \mathrm{U} / \mathrm{ml})$ did not inhibit fungal killing by ActPMN (table II) or ThioPMN, and catalase at the concentrations tested- $\leqslant 500,2000-5000,10000$ or $\geqslant 20000$ (maximum concentration tested, 42000 ) $\mathrm{U} / \mathrm{ml}$ in 3 to 9 experiments at each of these concentrations-did not inhibit killing of $B$. dermatitidis by ThioPMN (data not shown).

\section{Effect of other potential inhibitors of oxidative} microbicidal mechanisms on killing of $B$. dermatitidis by ActPMN and ThioPMN

$\mathrm{AZ}$ added to co-cultures at a concentration of 1 or $10 \mathrm{mM}$ significantly inhibited ActPMN killing of $B$. dermatitidis $(\mathrm{p}<0.001)$ (table II). AZ at $\leq 10 \mathrm{mM}$ had no direct effect on $B$. dermatitidis viability and did not significantly reduce killing of fungi by ThioPMN. A higher concentration of AZ (100 mM) was directly toxic to $B$. dermatitidis (18.0 SD $6.4 \%$ killing in $2 \mathrm{~h}, \mathrm{n}=2$ ) in the absence of PMN.

Scavenging of hydroxyl radical $(\cdot \mathrm{OH})($ Brummer

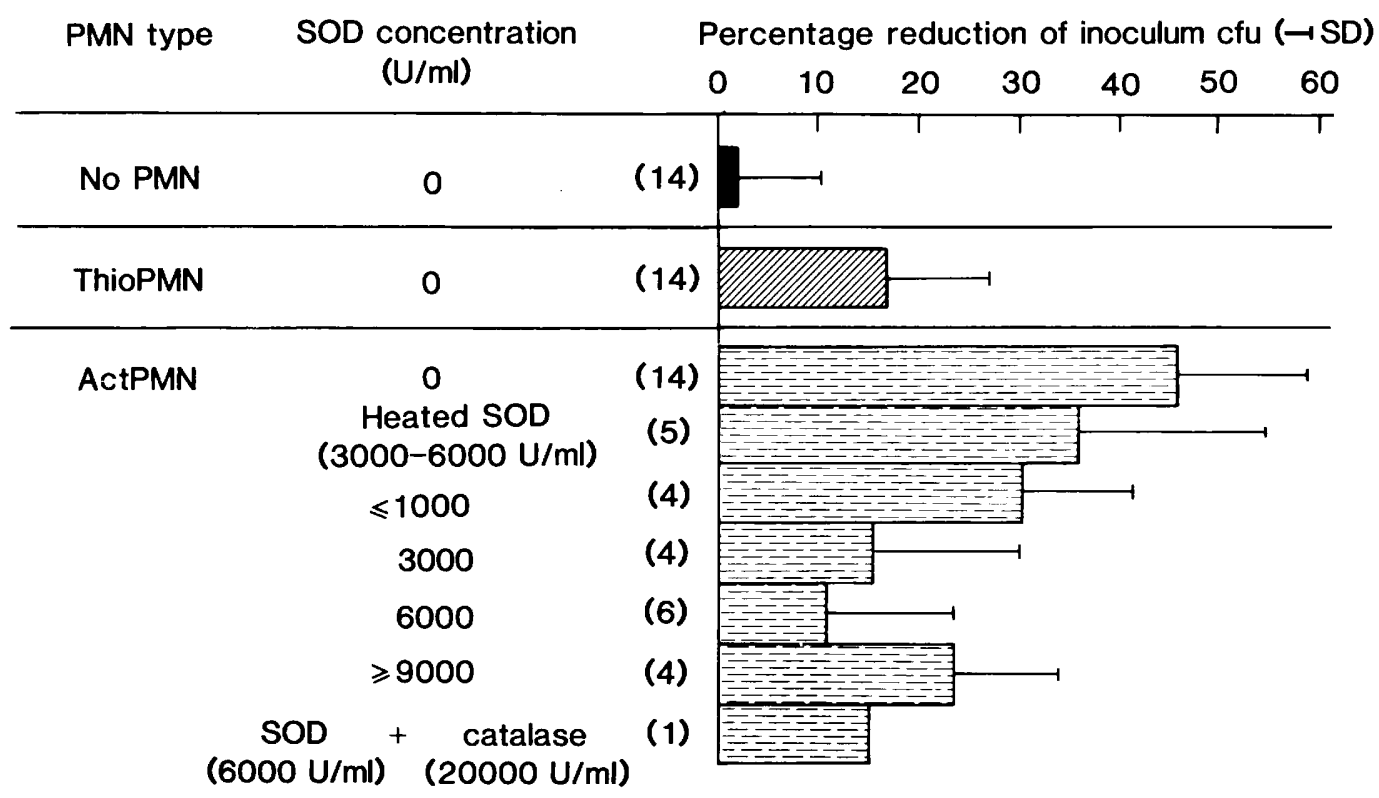

Figure. Effect of superoxide dismutase (SOD) concentration on reduction of inoculum cfu by PMN. SOD had no direct effect on $B$. dermatitidis viability and did not inhibit killing of $B$. dermatitidis by ThioPMN at the concentrations tested $(\leq 1000-\geq 9000 \mathrm{U} / \mathrm{ml}$ in 4-6 experiments). The mean percentage reduction of inoculum cfu and SD for the number of experiments in parentheses is given. 
Table II. Effect of potential inhibitors of oxidative microbicidal mechanisms on reduction of inoculum cfu by PMN*

\begin{tabular}{|c|c|c|c|c|c|}
\hline PMN type & Inhibitor added" & $\begin{array}{l}\text { Percentage reduction of } \\
\text { inoculum cfu }\end{array}$ & $\begin{array}{c}\text { Number of } \\
\text { experiments }\end{array}$ & $\begin{array}{c}\text { Percentage inhibition } \\
\text { of killing } \dagger\end{array}$ & p value \\
\hline No PMN & - & 1.4 & 14 & $\cdots$ & $\ldots$ \\
\hline ActPMN & $\begin{array}{lc}\text { None } & \\
\text { Catalase } & 2000-5000 \mathrm{U} / \mathrm{ml} \\
& 10,000 \mathrm{U} / \mathrm{ml} \\
& \geqslant 20,000 \mathrm{U} / \mathrm{ml} \\
\text { Heated catalase } \S \\
\text { Azide } & 0.1 \mathrm{mM} \\
& 1.0 \mathrm{mM} \\
& 10.0 \mathrm{mM} \\
\text { DMSO } & 300 \mathrm{mM} \\
\text { Benzoate } & 50.0 \mathrm{mM} \\
\text { Tryptophan } & 1.0 \mathrm{mM} \\
& 10.0 \mathrm{mM} \\
\text { Histidine } & 10.0 \mathrm{mM}\end{array}$ & $\begin{array}{l}44 \cdot 7 \\
31 \cdot 0 \\
21 \cdot 5 \\
29 \cdot 5 \\
48 \cdot 2 \\
36 \cdot 9 \\
16 \cdot 0 \\
16 \cdot 2 \\
29 \cdot 0 \\
26 \cdot 9 \\
25 \cdot 8 \\
0 \\
33 \cdot 6\end{array}$ & $\begin{array}{r}14 \\
9 \\
6 \\
3 \\
5 \\
5 \\
5 \\
3 \\
5 \\
2 \\
2 \\
2 \\
2\end{array}$ & $\begin{array}{c}\cdots \\
30 \cdot 6 \\
51 \cdot 9 \\
34 \cdot 0 \\
0 \\
17 \cdot 4 \\
64 \cdot 2 \\
63 \cdot 8 \\
35 \cdot 1 \\
39 \cdot 8 \\
42 \cdot 3 \\
100 \\
24 \cdot 8\end{array}$ & $\begin{array}{c}\quad \cdots \\
\text { n.s. } \\
<0.001 \\
\text { n.s. } \\
\cdots \\
\text { n.s. } \\
<0.001 \\
<0.001 \\
\text { n.s. } \\
\text { n.s. } \\
<0.001 \\
<0.001 \\
<0.01\end{array}$ \\
\hline ThioPMN & $\begin{array}{l}\text { None } \\
\text { Benzoate } 50.0 \mathrm{mM} \\
\text { Histidine } 1.0 \mathrm{mM} \\
10.0 \mathrm{mM}\end{array}$ & $\begin{array}{r}16 \cdot 4 \\
8 \cdot 9 \\
0 \cdot 3 \\
4 \cdot 4\end{array}$ & $\begin{array}{r}14 \\
2 \\
2 \\
2\end{array}$ & $\begin{array}{c}\cdots \\
45 \cdot 7 \\
98 \cdot 2 \\
73 \cdot 2\end{array}$ & $\begin{aligned} & \cdots \\
&< 0.05 \\
&<0.001 \\
&<0.02\end{aligned}$ \\
\hline
\end{tabular}

\footnotetext{
* For brevity of presentation, only those experiments where differences in reduction of inoculum cfu in cultures with potential inhibitors compared with the same PMN type containing no inhibitors was at least $7 \cdot 5 \%$ are shown. Not shown therefore are experiments (number of experiments in parentheses) with ActPMN and <500 U catalase (three), DMSO $3 \mathrm{mM}$ (five) and $30 \mathrm{mM}$ (three), tryptophan $0.1 \mathrm{mM}$ (two), histidine $0.1 \mathrm{mM}$ (two) and $1.0 \mathrm{mM}$ (two), and benzoate $10.0 \mathrm{~mm}$ (two) and $20 \mathrm{~mm}$ (two). Similarly, not shown are experiments with ThioPMN and catalase (see text); azide $0.1 \mathrm{mM}$ (four), $1.0 \mathrm{mM}$ (five) and 10.0 mM (three); DMSO 3 $\mathrm{mM}$ (four), $30 \mathrm{~mm}$ (three), and $300 \mathrm{mM}$ (five); tryptophan $0.1 \mathrm{~mm}$ (two), $1.0 \mathrm{~mm}$ (two), and $10.0 \mathrm{~mm}$ (two); histidine 1.0 mM (two); and benzoate $10.0 \mathrm{~mm}$ (two) and $20.0 \mathrm{~mm}$ (two). Results in none of these experiments were statistically significant.

$\uparrow$ Percent inhibition of killing by inhibitor for each PMN type compared to samples containing no inhibitor.

† Student's $t$ test, comparison between PMN killing with and without inhibitor for each PMN type; n.s. $=p>0 \cdot 05$.

$\S$ Catalase $(20000 \mathrm{U} / \mathrm{ml})$ was autoclaved at $121^{\circ} \mathrm{C}$ for $15 \mathrm{~min}$ before addition to PMN cultures.

"Final concentration of inhibitor in co-culture medium.
}

et al., 1985) with $300 \mathrm{mM}$ DMSO reduced ActPMN fungicidal activity by a mean of $35 \%$ (table II), but this reduction was not significant because of variability in the DMSO effects in repeated experiments resulting in a large SD. Lower concentrations of DMSO did not significantly reduce killing by ActPMN, nor were ThioPMN affected by any of the concentrations tested. DMSO had no direct effect on $B$. dermatitidis viability at the concentrations suggested to be inhibitory for ActPMN killing in table II, but a higher concentration $(2800 \mathrm{mM})$ of DMSO reduced inoculum cfu in the absence of $\operatorname{PMN}(95 \cdot 1 \%$ in $2 \mathrm{~h})$.

Another $\cdot \mathrm{OH}$ scavenger, sodium benzoate (Sasada and Johnston, 1980), inhibited ActPMN killing, but again only at the highest concentration tested, and not significantly, because of variability between experiments (table II). At this concentration, ThioPMN killing was significantly reduced. We also studied the effects of two agents which both quench ${ }^{1} \mathrm{O}_{2}$ and antagonise $\mathrm{HOCl}^{-}$, histidine and tryptophan, at previously studied concentra- tions (Hodgson and Fridovich, 1974; Singh and Valdez, 1978). The latter was a potent inhibitor of ActPMN killing, whereas the former inhibited ActPMN and was also the most potent inhibitor of ThioPMN killing (table II).

\section{Discussion}

It has been suggested that in luminol-dependent chemiluminescence studies (Brummer et al., 1984, 1985) an enhanced in-vitro fungicidal activity of ActPMN versus ThioPMN correlates with an increased oxidative burst by ActPMN upon stimulation with $B$. dermatitidis cells. We report here that ActPMN produce greater quantities of $\mathrm{O}_{2}{ }^{-}$in response to PMA than do ThioPMN. Furthermore, killing of $\mathrm{Bd}$ by ActPMN was inhibited by scavengers of active oxygen species. Exogenous superoxide dismutase, catalase, sodium azide, tryptophan and histidine and, to a lesser extent, DMSO and benzoate, inhibited killing when added to cultures immediately before fungal challenge. 
These data, in conjunction with the earlier reports (Brummer et al., 1984, 1985), indicate that the killing of $B$. dermatitidis by ActPMN involves one or more oxidative mechanisms, and suggest a prominent role for $\mathrm{O}_{2}{ }^{-}$, a probable role for $\mathrm{H}_{2} \mathrm{O}_{2}$, and possible roles for ${ }^{1} \mathrm{O}_{2}, \mathrm{HOCl}^{-}$and $\cdot \mathrm{OH}$ in fungal killing by ActPMN. Because $\mathrm{O}_{2}{ }^{-}$and $\mathrm{H}_{2} \mathrm{O}_{2}$ are responsible for the formation of $\cdot \mathrm{OH}$ and ${ }^{1} \mathrm{O}_{2}$, scavengers that interfere with the activity of $\mathrm{O}_{2}{ }^{-}$ or $\mathrm{H}_{2} \mathrm{O}_{2}$ or both may also interfere with the production of $\cdot \mathrm{OH}$ and ${ }^{1} \mathrm{O}_{2}$, as well as other products of $\mathrm{H}_{2} \mathrm{O}_{2}$. Therefore, the direct contribution of $\mathrm{O}_{2}{ }^{-}$and $\mathrm{H}_{2} \mathrm{O}_{2}$ to fungal killing may be less profound than indicated by the results with scavengers of these compounds, as these scavengers may also indirectly remove more distal oxidative compounds that contribute to fungal killing.

The action of SOD to produce $\mathrm{H}_{2} \mathrm{O}_{2}$ from $\mathrm{O}_{2}{ }^{-}$ would be expected to suppress microbicidal reactions dependent upon $\mathrm{O}_{2}^{-}$and enhance those dependent upon $\mathrm{H}_{2} \mathrm{O}_{2}$. Because SOD markedly suppresses fungicidal activity, $\mathrm{H}_{2} \mathrm{O}_{2}$ alone is probably a less potent killing agent than $\mathrm{O}_{2}{ }^{-}$or its byproducts. $\mathrm{H}_{2} \mathrm{O}_{2}$ may serve as the precursor of ${ }^{1} \mathrm{O}_{2}$ or $\cdot \mathrm{OH}$ upon interaction with $\mathrm{O}_{2}^{-}$(Badwey and Karnovksy, 1980). The addition of SOD to cultures may have resulted in the removal of $\mathrm{O}_{2}{ }^{-}$before it could react with $\mathrm{H}_{2} \mathrm{O}_{2}$ to form toxic oxygen metabolites further along the oxidative pathway, thereby inhibiting ActPMN fungicidal activity.

Although catalase significantly reduced fungal killing by ActPMN, the addition of catalase in conjunction with SOD did not reduce killing further. Residual killing activity by ActPMN after SOD treatment was, therefore, not due to $\mathrm{H}_{2} \mathrm{O}_{2}$ formation catalysed by SOD, because $\mathrm{H}_{2} \mathrm{O}_{2}$ would have been destroyed by the addition of catalase and killing would have been further inhibited.

The reduction of ActPMN killing activity by sodium azide may have been partly due to its removal of ${ }^{1} \mathrm{O}_{2}$ (Hasty et al., 1972). Sodium azide has also been shown to inactivate MPO, the enzyme mediating the MPO- $\mathrm{H}_{2} \mathrm{O}_{2}$-halide killing system of PMN (Klebanoff and Clark, 1978). This system generates $\mathrm{HOCl}^{-}$, which is microbicidal. Thus, azide may have also acted to eliminate oxidative killing mechanisms dependent upon $\mathrm{H}_{2} \mathrm{O}_{2}$.

The activity of tryptophan and histidine, which also have potential activity against both ${ }^{1} \mathrm{O}_{2}$ and $\mathrm{HOCl}^{-}$, in inhibiting ActPMN killing again emphasises the possible role of one or both of these potentially cidal oxidative by-products in fungal killing by ActPMN.

Hydroxyl radical $(\cdot \mathrm{OH})$ is not the most likely mediator of ActPMN killing activity based on data obtained with DMSO and benzoate as $\cdot \mathrm{OH}$ scavengers. These agents inhibited ActPMN fungicidal activity by $35 \%$ and $40 \%$, respectively, which, while suggestive, was not significantly inhibitory, and required the highest concentrations studied. However, previous work (Brummer et al., 1985) has demonstrated reduced chemiluminescence in the presence of $300 \mathrm{~mm}$ DMSO, suggesting a possible role for $\cdot \mathrm{OH}$ in ActPMN fungicidal mechanisms. Other scavengers of $\cdot \mathrm{OH}$ might allow a further assessment of the contribution of $\cdot \mathrm{OH}$ to fungal killing.

The absence of inhibition of the small amount of ThioPMN-mediated killing of fungi by almost all the oxidative scavengers studied indicates that ThioPMN may use primarily non-oxidative mechanisms in their limited capacity for fungal killing. Non-oxidative microbicidal mechanisms using lysosomes or granule-associated cationic proteins are known to exist in rabbit, human and guinea pig PMN (Lehrer et al., 1975; Spitznagel and Shafer, 1985). Whether or not non-oxidative pathways are involved in ThioPMN killing of $\boldsymbol{B}$. dermatitidis is worth investigation. Residual killing by ActPMN, after SOD treatment, may reflect the alternative non-oxidative fungicidal mechanisms present in these cells. No direct effects on the viability of $B$. dermatitidis were observed at the optimal concentrations of scavengers used to inhibit PMN killing in this study, and no effects on chemotaxis or the attachment of PMN to $B$. dermatitidis were found in the presence of the scavengers employed (unpublished observations).

These data indicate that the ActPMN killing of $B$. dermatitidis involves one or more active oxygen species but does not rule out a contribution by nonoxidative mechanisms as well. ThioPMN killing of $B$. dermatitidis, although limited, is presumably mediated by predominantly non-oxidative mechanisms, because killing is generally not inhibited by scavengers of oxidative metabolites. Based on the enhanced production of $\mathrm{O}_{2}{ }^{-}$by ActPMN and the efficacy of inhibition of killing by oxygen metabolite scavengers, the agents responsible for ActPMN fungicidal activity appear to be primarily $\mathrm{O}_{2}{ }^{-}$or mechanisms dependent on $\mathrm{O}_{2}{ }^{-}$production, with a probable role for $\mathrm{H}_{2} \mathrm{O}_{2}$, and possible involvement by ${ }^{1} \mathrm{O}_{2}, \mathrm{HOCl}^{-}$and $\cdot \mathrm{OH}$ as well.

This study was supported by a contract (\# N00014-83-K0018) with the Office of Naval Research, US Navy. The results were presented in part to the 22nd National Meeting of the Reticuloendothelial Society, Ithaca, NY, 1985. We thank Chiyo Inouye for assistance with the manuscript. 


\section{REFERENCES}

Badwey J A, Karnovsky M L 1980 Active oxygen species and the functions of phagocytic leukocytes. Anmual Review of Biochemistry 49: 695-726.

Beers R F, Sizer I W 1952 A spectrophotometric method for measuring the breakdown of hydrogen peroxide by catalase. Journal of Biological Chemistry 195: 133-140.

Brummer E, Stevens D A 1983 Enhancing effect of murine polymorphonuclear neutrophils (PMN) on the multiplication of Blastomyces dermatitidis in vitro and in vivo. Clinical and Experimental Immunology 54: 587-594.

Brummer E, Stevens D A 1984 Activation of murine polymorphonuclear neutrophils for fungicidal activity with supernatants from antigen-stimulated immune spleen cell cultures. Infection and Immunity 45: 447-452.

Brummer E, Sugar A M, Stevens D A 1984 Immunological activation of polymorphonuclear neutrophils for fungal killing: studies with murine cells and Blastomyces dermatitidis in vitro. Journal of Leukocyte Biology 36: 505-520.

Brummer E, Sugar A M, Stevens D A 1985 Enhanced oxidative burst in immunologically activated but not elicited polymorphonuclear leukocytes correlates with fungicidal activity. Infection and Immunity 49: 396-401.

Hasty N, Merkel P B, Radlick P, Kearns D R 1972 Role of azide in singlet oxygen reactions. Reaction of azide with singlet oxygen. Tetrahedron Letters 1 : 49-52.

Hodgson E K, Fridovich I 1974 The production of superoxide radical during the decomposition of potassium peroxochromate (V). Biochemistry 13: 3811-3815.
Johnston R B et al. 1975 The role of superoxide anion generation in phagocytic bactericidal activity. Studies with normal and chronic granulomatous disease leukocytes. Journal of Clinical Investigation 55: 1357-1372.

Klebanoff S J, Clark R A 1978 The neutrophil: function and clinical disorders. North-Holland, Amsterdam, p. 283.

Lehrer R I, Ladra K M, Hake R B 1975 Nonoxidative fungicidal mechanisms of mammalian granulocytes: demonstration of components with candidacidal activity in human, rabbit, and guinea pig leukocytes. Infection and Immunity 11 : 1226 1234.

Lowry O H, Rosebrough N J, Farr A L, Randall R J 1951 Protein measurement with the folin phenol reagent. Journal of Biological Chemistry 193: 265-275.

Morozumi P A, Brummer E, Stevens D A 1982 Protection against pulmonary blastomycosis: correlation with cellular and humoral immunity in mice after subcutaneous nonlethal infection. Infection and Immunity 37: 670-678.

Sasada M, Johnston R B 1980 Macrophage microbicidal activity: correlation between phagocytosis-associated oxidative metabolism and the killing of Candida by macrophages. Journal of Experimental Medicine 152 : 85-98.

Singh H, Vadas J A 1978 Singlet oxygen: a major reactive species in the furocoumarin photosensitized inactivation of E. coli ribosomes. Photochemistry and Photobiology 28: 539545.

Spitznagel J K, Shafer W M 1985 Neutrophil killing of bacteria by oxygen-independent mechanisms : a historical summary. Reviews of Infectious Diseases 7: 398-403. 